\title{
Biologia e morfologia de Gyropsylla spegazziniana (Lizer y Trelles) (Hemiptera, Psyllidae) ${ }^{1}$

\author{
Biology and morphology of \\ Gyropsylla spegazziniana (Lizer y Trelles) \\ (Hemiptera, Psyllidae) ${ }^{1}$
}

Maria S. P. LeITE ${ }^{2}$

\& KetI M. R. ZANOL ${ }^{3}$

Gyropsylla spegazziniana (Lizer y Trelles, 1919), conhecida como ampola-da-erva mate, é considerada a segunda praga da erva-mate (Ilex paraguariensis St.-Hil.,1822 (Aquifoliacea)). Apesar dos danos provocados pouco se conhece a respeito da sua biologia e os trabalhos que tratam do assunto (Oglobin, 1929, De Cool \& Saini, 1992; Morawick, 1995; SABEDOt et al., 1999, Chiaradia et al, 2000) o fazem de maneira sucinta.

Na morfologia aspectos do ovo, ninfas e adultos são apresentados na forma de desenhos (OGLOBIN, 1929) sem maiores detalhes.

Este estudo tem como objetivo descrever a biologia e aspectos comportamentais da G. spegazziniana, em condições de laboratório como também caracterizar os diferentes estágios.

\footnotetext{
'Contribuição no 1373 do Departamento de Zoologia , SCB, Universidade Federal do Paraná. - Caixa Postal 19020 - 81531-990 Curitiba, Paraná, Brasil. ${ }^{2}$ Curso de Pós-Graduação em Ciências Biológicas (Entomologia), ${ }^{3}$ Idem (Orientadora).
} 


\section{MATERIAL E MÉTODOS}

O experimento foi realizado no laboratório de Entomologia da Embrapa/ Floresta, em Colombo, Paraná, em três etapas: 1. observação da biologia; 2. determinação da longevidade e 3. caracterização da espécie.

\section{Biologia}

O experimento foi realizado em duas etapas: $1^{\text {a }}$ etapa: experimento realizado com cinco repetições, no período de março e abril de 2000, com temperatura e umidade ambiente registradas através de um termohigrógrafo, cuja média foi de $25,6 \pm 3^{\circ} \mathrm{C}$ e $48,8 \pm 10 \%$, respectivamente; fotofase de 12 horas. $2^{\text {a }}$ etapa: experimento realizado com seis repetições, de outubro de 2001 a janeiro de 2002, temperatura e umidade ambiente registradas através de um termohigrógrafo, cuja média foi de $19,5+3^{\circ} \mathrm{C}$ e $79,3+10 \%$, respectivamente; fotofase de 12 horas.

Em cada uma das etapas utilizou-se quatro machos para cada fêmea recém emergidos obtidos através de galhas quase abertas, coletadas no campo e mantidas no laboratório. Após a sexagem, as giropsílas foram transportadas para gaiola de acrílicoâ subdividida em quatro compartimentos, onde mudas de erva-mate, com aproximadamente $15 \mathrm{~cm}$ de altura foram colocadas. Os compartimentos eram separados por aletas de acrílico que quando levantadas permitiam a passagem dos indivíduos para outra muda (Fig. 1).

As giropsílas permaneceram uma semana na primeira muda e com uma das aletas levantadas e com auxílio de um pincel umidecido, foram semanalmente removidas para nova muda até a morte das fêmeas.

As mudas atacadas permaneceram em sacos plásticos comerciais e foram acondicionadas em gaiolas de plástico até a emergência da prole. Esta era formada com um vaso de plástico com $16,5 \mathrm{~cm}$ de diâmetro e $19,0 \mathrm{~cm}$ de altura e uma película de PVC sobre a parte superior deixando apenas a parte aérea da planta; encaixando no vaso colocou-se outro com as mesmas dimensões, em posição invertida cujo fundo foi retirado e coberto com "voil" de $30 \mathrm{~cm}^{2}$, preso com elástico. (Fig. 2).

As observações foram diárias em horários alternados, durante duas horas, registrando-se o número de galhas formadas, aspectos da biologia, do comportamento e a longevidade das fêmeas. Como não foi possível observar o dia exato em que começaram as posturas inferiu-se que os ovos foram colocados nos 3,5 dias.

Neste experimento não foi possível observar o número de ovos por 
isso ramos atacados foram coletados, no erval da Embrapa-Floresta e com auxílio de uma lupa 10 folhas pregadas foram abertas e os ovos contados.

As mensurações foram obtidas com ocular micrométrica, de um microscópio óptico Zeiss Axioplan2, com aumento de 10X; foram medidos 40 ovos sem pedúnculo, 147 ninfas e 60 adultos.

\section{LONGEVIDADE}

O experimento, com cinco repetições, foi instalado, em fevereiro de 2000, em laboratório com fotofase de 12 horas, temperatura e umidade de $25,6^{\circ} \mathrm{C}$ e $48,810 \%$ respectivamente, registradas através de um termohigrógrafo. As giropsílas, três machos para cada fêmea, foram colocadas em gaiola de acrílicoâ , na qual continha uma muda de erva-mate com aproximadamente $15 \mathrm{~cm}$ de altura (Fig. 1). Para não haver interferência na longevidade, as giropsílas foram manipuladas somente na instalação do experimento; quando houve necessidade de mais substrato, outra muda era colocada dentro da gaiola. Os adultos foram observados diariamente até a morte registrando-se os dados da longevidade dos machos e das fêmeas. Como algumas fêmeas morreram cedo, estas foram substituídas porém não foram consideradas no cálculo.

\section{CARACTERIZAÇÃO DA GYROPSYLLA SPEGAZZINIANA}

Brotações de erva-mate, com diferentes estágios de galhas, foram coletados no erval da Embrapa-Floresta; estas foram abertas com auxílio de um estilele e/ou gilete. Os ovos e as ninfas foram retiradas das galhas e preservadas em álcool 70. Os adultos foram obtidos através de galhas quase abertas coletadas no campo.

\section{RESULTADOS E DISCUSSÃO}

\section{Biologia}

Os psilídeos recém emergidos permaneciam com pouca mobilidade nas paredes da gaiola ou no solo. A partir do quarto dia os machos começaram a buscar as brotações enquanto que as fêmeas a fizeram entre quinto e o oitavo dia. Seguidamente, machos e fêmeas reunidos, nas brotações, efetuavam cópulas repetidas seguidas pela introdução do ovipositor na brotação. As fêmeas copulavam com mais de um macho ao contrário do observado por MoRAWICKI et al. (1995) que observaram a seleção de um macho pela fêmea, com cópulas repetidas. 
No momento da postura a fêmea picava a nervura central, movia o corpo para trás, abria as asas e inseria seu ovipositor nas folhas jovens, ainda fechadas. Enquanto a fêmea realizava a postura, os machos permaneciam próximos. Logo após um dos machos se aproxima da fêmea e uma nova copula ocorria; este ritual demorava horas. OGLOBIN (1929a) observou que ao mesmo tempo em que a fêmea fazia a oviposição picava a nervura central introduzindo uma substância albuminosa.

Não foi possível observar o número exato de posturas realizadas por cada fêmea visto que os ovos eram inseridos no interior das brotações, entretanto o número de galhas com posturas foi em média 2,9 galhas por fêmea (Tabela 1). SABEDOt (1999) e ChiARAdia et al. (2000) observaram em média de duas posturas, contudo não foi citado de que forma estas foram consideradas.

O número de ovos foi bastante variado podendo ocorrer de oito até 100 ovos dispostos em um ou quatro grupos. Morawich et al. (1995) observaram de 35 a 180 ovos enquanto que SABEDot et al. (1999) e ChiARAdia et al (2000) observaram em média $22,97+1,96$ ovos na primeira postura e $6,84+2,21$ ovos na segunda postura.

Os ovos, sem o pedúnculo, mediram aproximadamente $0,35 \mathrm{~mm}$ valor aproximado ao obtido por SABEDOT et al. (1999) e CHIARADIA et al (2000) que obtiveram $0,36 \mathrm{~mm}$.

RIVERA FlORES (1983) observou que a eclosão ocorria de seis a sete dias após a postura e MoRAWICK et al (1995) observaram que o estágio de ovo durou sete dias.

O número de descendentes foi em média 13,1 numa proporção de 1 macho para 2 fêmeas (Tabela 1), distinta da encontrada por MoRAwicki et al. (1995) e ChIARADIA et al. (2000) que obtiveram uma proporção de 1:1.

No desenvolvimento pós-embrionário observou-se cinco estádios. MoRAWICK et al. (1995) observaram quatro estádios com uma longevidade de sete dias para cada, completando o seu desenvolvimento em 28 dias. SABEDOT et al. (1999) através de medidas da cápsula cefálica afirmaram não ser possível determinar se estas passavam por quatro ou cinco ínstares enquanto que CHIARADIA et al. (2000) observaram cinco ínstares.

As ninfas de último estádio abandonam as galhas e dirigem-se para a parte abaxial da folha, ocorrendo a ecdise nas horas matinais ou no ocaso, ficando a exúvia branca aderida à folha (Fig.3 A). Quando da emergência, os adultos, permaneciam imóveis durante horas, com as asas pregadas, moles e de coloração leitosa adquirindo, gradativamente, firmeza e coloração definitiva. 
Tabela 1: Postura, número de galhas formadas, longevidade das fêmeas, proporção sexual dos adultos obtidos de Gyropsylla spegazziniana e duração de ovo a adulto, obtidos no laboratório - 2000/ 2001.

\begin{tabular}{|c|c|c|c|c|c|c|c|c|}
\hline $\begin{array}{l}\text { Repetições } 1 \\
1^{\underline{a}} \text { etapa } \\
\text { mar/abril/00 } \\
25,6^{\circ} \mathrm{C} \mathrm{e} \\
48,8 \% \text { UR }\end{array}$ & $\begin{array}{l}1^{\underline{a}} \text { postura } \\
\text { (dias) }\end{array}$ & $\begin{array}{l}\mathrm{N}^{\circ} \mathrm{de} \\
\text { posturas } \\
\text { por galha }\end{array}$ & $\begin{array}{l}\mathrm{N}^{\mathrm{o}} \mathrm{de} \\
\text { Galhas } \\
\text { forma- } \\
\text { das }\end{array}$ & $\begin{array}{l}\text { Longevidade } \\
\text { das fêmea } \\
\text { (dias) }\end{array}$ & macho & fêmea & Total & $\begin{array}{l}\text { Duração de } \\
\text { ovo-adulto } \\
\text { (dias) }\end{array}$ \\
\hline 1 & 7 & 2 & 4 & 31 & 0 & 23 & 23 & 35 e 35 \\
\hline 2 & 14 & 1 & 1 & 17 & 0 & 1 & 1 & 41 \\
\hline 3 & 7 & 1 & 2 & 11 & 9 & 10 & 19 & 37 \\
\hline 4 & 7 & 3 & 6 & 46 & 8 & 10 & 18 & $50-47-42$ \\
\hline 5 & 5 & 2 & 2 & 14 & 0 & 14 & 14 & $42-40$ \\
\hline Média & 8 & 1,8 & 3 & 23,8 & 3,4 & 11,6 & 15 & 41 \\
\hline
\end{tabular}

$2^{\underline{a}}$ etapa out/dez/01 $19,5^{\circ} \mathrm{C}$ e $79,3 \%$ UR

$\begin{array}{lcccccccc}6 & 9 & 1 & 2 & 18 & 1 & 0 & 1 & 32 \\ 7 & 5 & 1 & 3 & 15 & 8 & 12 & 20 & 35 \\ 8 & 10 & 1 & 6 & 15 & 7 & 17 & 24 & 33 \\ 9 & 8 & 1 & 2 & 22 & 1 & 0 & 1 & 37 \\ 10 & 5 & 1 & 1 & 15 & 4 & 7 & 11 & 34 \\ 11 & 5 & 1 & 3 & 15 & 9 & 3 & 12 & 41\end{array}$

\begin{tabular}{lllllllll} 
Média & 7 & 1 & 2,8 & 16,6 & 5,0 & 6,5 & 11,5 & 35,3 \\
\hline Média total 7,4 & 1,3 & 2,9 & 19,9 & 4,2 & 8,8 & 13,1 & 38,7 \\
\hline
\end{tabular}


O período desde a emergência do adulto até a primeira introdução do ovipositor na folha levou em média 7,4 dias, porém em três repetições, as posturas foram efetuadas no quinto dia (Tabela 1). Nos estudos realizados por OGLobin (1929) as fêmeas levaram em média de oito a quinze dias para realizarem as primeiras posturas enquanto SABEDOT et al. (1999) e Chiaradia et al. (2000) consideraram uma média de 4,41 dias como pré-postura.

A maioria dos adultos originados de uma mesma galha emergiram no mesmo dia entretanto alguns emergiram em dias distintos, porém em datas próximas. O período compreendido desde o ovo até o adulto foi 38,7 dias (Tabela 1), distinta daqueles encontrados por MoRAWICKI et al. (1995) e ChiARAdia et al. (2000) que foram de 35 dias e 27,3 dias, respectivamente.

O comprimento das fêmeas variou de $2,2 \mathrm{~mm}$ a $3,4 \mathrm{~mm}$, com média de 2,9 $\mathrm{mm}$ e nos machos de 2,0 $\mathrm{mm}$ a 2,9 $\mathrm{mm}$, com média de 2,6 $\mathrm{mm}$. Oglobin (1929) observou uma variação de $2 \mathrm{~mm}$ a $4 \mathrm{~mm}$. De Coll \& SAINI (1992) observaram que os machos medem 2,2 mm enquanto que as fêmeas 2,6 mm. Segundo Morawick et al (1995) os machos medem 3 $\mathrm{mm}$ e as fêmeas $4 \mathrm{~mm}$. ChIARAdia et al. (2000) informaram que os adultos medem $3 \mathrm{~mm}$.

A longevidade somente das fêmeas, ou seja quando houve manipulação na criação, foi 23,8 dias na $1^{\text {a }}$ etapa e de 16,6 dias na segunda etapa com uma média de 19,9 dias (Tabela 1)

A longevidade dos adultos, quando não houve manipulação na criação, foi de 43,7 dias para os machos e 15,2 dias para as fêmeas. O ciclo completo foi de 82,4 dias para os machos e de 53,9 dias para as fêmeas. Para Oglobin (1929) o ciclo completo leva 40 dias enquanto Rivera FloRES (1983) observou o ciclo entre 30 a 40 dias. MoRAWICK et al (1995) observaram que os machos tinham uma longevidade de 28 dias a 32 dias enquanto que as fêmeas duravam de oito a 12 dias; o ciclo completo levou 65 dias para os machos e 45 dias para as fêmeas. SABEDOT et al. (1999) observaram a longevidade das fêmeas em 9,24 dias e dos machos 12 dias cujo ciclo total foi de 27,29 dias. CHIARADIA et al. (2000) observaram uma longevidade de 9,24 dias para as fêmeas e 12 dias para os machos.

Quando comparamos os resultados dos diferentes trabalhos observase uma diferença em relação aos dados numéricos. A maioria dos trabalhos não descreveram a metodologia adotada exceto SABEDOT et al (1999). Comparando a metodologia adotada por estes autores e as deste trabalho 
pode-se atribuir que estas diferenças estão associadas ao método de criação associado a oferta de substrato (erva-mate) para alimentação e postura. Neste trabalho foi ofertado, semanalmente, uma nova muda de erva-mate até a morte das fêmeas enquanto que SABEDOT et al. (1999) ofertaram apenas uma muda de erva-mate, durante todo o experimento.

\section{CARACTERIZAÇÃo dA Gyropsylla SPEGAZZINIANA} (LizER Y TRELLES, 1919)

GALHA - A galha apresenta inicialmente o aspecto de uma folha pregada contendo os ovos. Com o desenvolvimento das ninfas, a galha vai crescendo e gradativamente assume a forma de uma ampola (Figs 4 a-d). Junto as nervuras, o parênquima adquire a coloração violácea (Figs 4 b; 6). OGLOBIN (1929) relatou que esta coloração é devido a produção anormal de antocianina. Quando as ninfas completam seu desenvolvimento a galha se abre liberando-a (Fig. 5).

OVOS - Os ovos são elípticos, pedunculados, translúcidos e de coloração esbranquiçada; junto ao pedúnculo, apresentam coloração amarelo clara. A medida que se aproxima da eclosão é possível observar os olhos vermelhos (Fig. 6). A base do pedúnculo, que fica inserida na folha é alargada e marrom-escura. A forma e a coloração corroboram OGLOBIN (1929) que observou a coloração branca e amarelo vivo junto ao pedúnculo enquanto que SABEDOT et al. (1999) observaram a coloração verde amarelado e ChIARADIA et al. (2000) observaram a coloração amarelada. Em algumas posturas os ovos estavam dispostos em forma de roseta corroborando as observações de OGlobin (1929) e De Cool \& SAINI (1992) porém a maioria deles, encontravam-se agrupados próximos à nervura central.

NINFAS - As ninfas apresentam o corpo achatado dorso-ventralmente com inúmeras cerdas e coberto por substância pulverulenta branca, produzidas pelas glândulas cercígenas (também chamadas de circunanal), ao redor do orifício anal (Fig. 19, 20). As ninfas excretam uma substância açucarada, em forma de gotículas que ficam envolvidas por substância pulverulenta (Fig. 7); nas ninfas de $1^{\circ}$ e $2^{\circ}$ estádio esta pode se romper assumindo o aspecto de tubo alongado. As ninfas de $1^{\circ}$ estádio (Figs 6,8) apresentam o corpo ovalado, de cor amarelo-pálido. Cabeça bem desenvolvida com olhos avemelhados; as antenas amarelas com dois artículos. Pernas com unhas e arólio; tarsos ausentes. As ninfas do $2^{\circ}$ estádio (Fig. 9) apresentam cor amarelo-pálido. Olhos vermelhos. 
Antenas amarelas com dois artículos (Fig. 10). Pernas com unhas e arólio; tarsos ausentes. As ninfas de $3^{\circ}$ estádio (Fig. 11) apresentam o corpo amarelo-pálido. Olhos avermelhados. Antenas com quatro artículos (Fig. 12). Tórax com brotos alares. Pernas com unhas e arólio; tarsos ausentes. As ninfas de $4^{\circ}$ estádio (Fig. 13) apresentam o corpo amarelado. Olhos proeminentes, acinzentados com uma mancha vermelha. Antenas amarelas com sete artículos; artículo apical marrom com estriações circulares (Fig. 14). Tecas alares desenvolvidos. Pernas com unhas e arólio; tarsos ausentes (Fig. 15). As ninfas de $5^{\circ}$ estádio (Figs 3 A, 16) apresentam o corpo geralmente verde-claro, com tagmas distintos porém em alguns espécimens a coloração é amarelada. Cabeça, em vista dorsal, mais larga do que longa. Olhos acinzentados com uma mancha vermelha. Antenas amarelas com nove artículos; artículo apical marrom com estriações circulares (Fig. 17). Tégulas presentes; tecas alares desenvolvidas, amareladas, com impressões da venação. Pernas com um tarsômero, unhas e arólio. (Fig. 18).

SABEDOT et al. (1999) observaram que as ninfas dos primeiros estádios eram amareladas e às de $4^{\circ}$ ou $5^{\circ}$ estádios eram amarelo-esverdeadas e que nestes os olhos vermelhos eram bem definidos e o corpo estava coberto por substância pulverulenta. CHIARADIA et al. (2000) observaram que os três primeiros ínstares apresentavam a cor amarelada e às de $4^{\circ}$ e $5^{\circ}$ ínstares eram amarelo-esverdeada.

Existe uma certa divergência com relação a quantos estádios passa a giropsíla, quatro ou cinco. Esta pode estar entre o $1^{\circ}$ e $2^{\circ}$ estádios que são muito pequenos e semelhantes quanto a forma do corpo.

O corpo das ninfas encontra-se coberto por substância pulverulenta bem como a cor vermelha dos olhos são observados em todos os estádios (1-5); este inclusive pode ser visualizado no ovo devido a translucidez do córion (Fig. 6).

ADULTOS - MACHO (Figs 3 A e B). Cabeça, em vista dorsal, amarela-esverdeada. Vértice dividido por um sulco longitudinal. Olhos proeminentes acinzentados. Ocelos em número de três sendo dois dorsais, junto aos olhos (Fig. 21) e um ventral, na fronte (Fig. 22). Face amarelaesverdeada. Clípeo-labro ovalado e intumescido. Lábio com três artículos; ápice preto (Fig. 22). Antenas com os três primeiros artículos amarelos e os outros sete marrom-escuros; escapo e pedicelo com textura imbricada e os demais com estriações circulares; artículo apical com duas cerdas sensoriais (Fig. 23). Tórax com as pleuras e esternos marrons. 
Pronoto estreito de cor verde. Mesonoto esverdeado com três áreas amarelas e duas manchas arredondadas marrom-escuras. Metanoto esverdeado. Tégulas esverdeadas. Asas transparentes com venação marrom; uma mancha marrom-escura na base (Fig. 3 C). Pernas com dois tarsômeros, um par de unhas pretas e arólio (Fig. 24). Pernas protorácicas marrom-claras. Pernas mesotorácica fulvas; fêmures com metade basal marrom-escuros. Pernas mesotorácicas com fêmures marrom-escuros, tíbias e tarsos amarelados. Abdômen verde; terminália (Fig. 25). Pigóforo (PG), em vista lateral, de contorno irregular com inúmeras cerdas. Placa subgenital (PL) triangular. Parâmeros (ES) retangulares com pequenas cerdas dispersas; ápice esclerotinizado. Edeago curvo; ápice alargado e com um processo dentiforme dorsal.

FÊMEA (Figs 3 A, D e E). Externamente semelhante ao macho. Terminália marrom-escura. Pigóforo (PG) triangular, pontiagudo com inúmeras cerdas. Abertura anal (a), na base do pigóforo, bem desenvolvida, de forma ovalada, circundada por inúmeras cerdas e pelas aberturas das glândulas cericígenas (Figs 3E e 26). Sétimo esterno (ST) triangular. Ovipositor (OV) com dois pares de valvas; o par dorsal, mais ou menos espatulado e transversalmente estriado; o par ventral reto e maior que o dorsal.(Fig. 27).

\section{RESUMO}

Aspectos da biologia e comportamentais de Gyropsylla spegazziniana (Lizer y Trelles) em condições de laboratório, foram estudados. O período de desenvolvimento do ovo à emergência do adulto foi de 38,7 dias, a longevidade do macho foi de 43,7 dias e das fêmeas foi de 15,2 dias. Ovos, ninfas e adultos foram descritos e ilustrados.

Palavras Chaves: Biologia, Hemiptera, Gyropsylla, Morphologia, Psyllidae

\section{SUMMARY}

Biological aspects and behaivour of Gyropsylla spegazziniana (Lizer y Trelles), under laboratory conditions, were studied. Mean development time of immature stages to immago was 38,7 days; the longevity of the 
male was 43,7 days and the female was 15,2 days. Eggs, nymphs and adults are described and illustrated.

Key words: Biology, Hemiptera, Gyropsylla, Morphology, Psyllidae.

\section{RÉSUMÉ}

Ce travail se rapporte aux aspectes du comportement et de la biologie de Gyropsilla spegazziniana (Lizer y Trelles) au laboratoire. Le temps de développement, oeuf jusqu' 'a l'occurrence du adulte a été 38,7 jours, la longévité des mâles a été 43,7 jours et des femelles a été 15,2 jours. Oeuf, nymphes et adultes sont décrites et ilustreés.

Mots ClÉs: biologie, Hemiptera, Gyropsylla, morphologie, Psyllidae.

\section{BIBLOGRAFIA}

Chiaradia, L. A.; J. M. Milanez \& S.M. Sabedot. 2000. Caracterização e danos da ampola-da-erva-mate. Pesquisa Agropecuária Gaúcha 13(1): 50-53.

De CoOL, O.R. \& E.D. SAINI. 1992. Insectos y acaros prejudiciales al cultivo de la yerba mate en la Republica Argentina. INTA: 1-48.

Morawicki, P.M.; C. I. F. Díaz \& A. E.Tricio. 1995. Ciclo de vida de Gyropyilla spegazziniana (1.,1917) Psyllidae-Homoptera. “ Psilídeo de la yerba mate". In: Congresso Argentino de Entomologia, 3: 299.

Oglobin, A A 1929. Metamorfosis de Metaphalaria spegazziniana (Liz.) Crwf. Rev. Yerbateira, 3: 15-18

Sabedot, S. M.; J.M. Milanez; F. R. M. Garcia \& L. A Chiaradia. 1999. Biologia de Gyropsylla spegazziniana (Lizer, 1917) (Hemiptera: Psyllidae) em laboratório. Acta Biol. Leopoldensia 21(2): 203-212. 


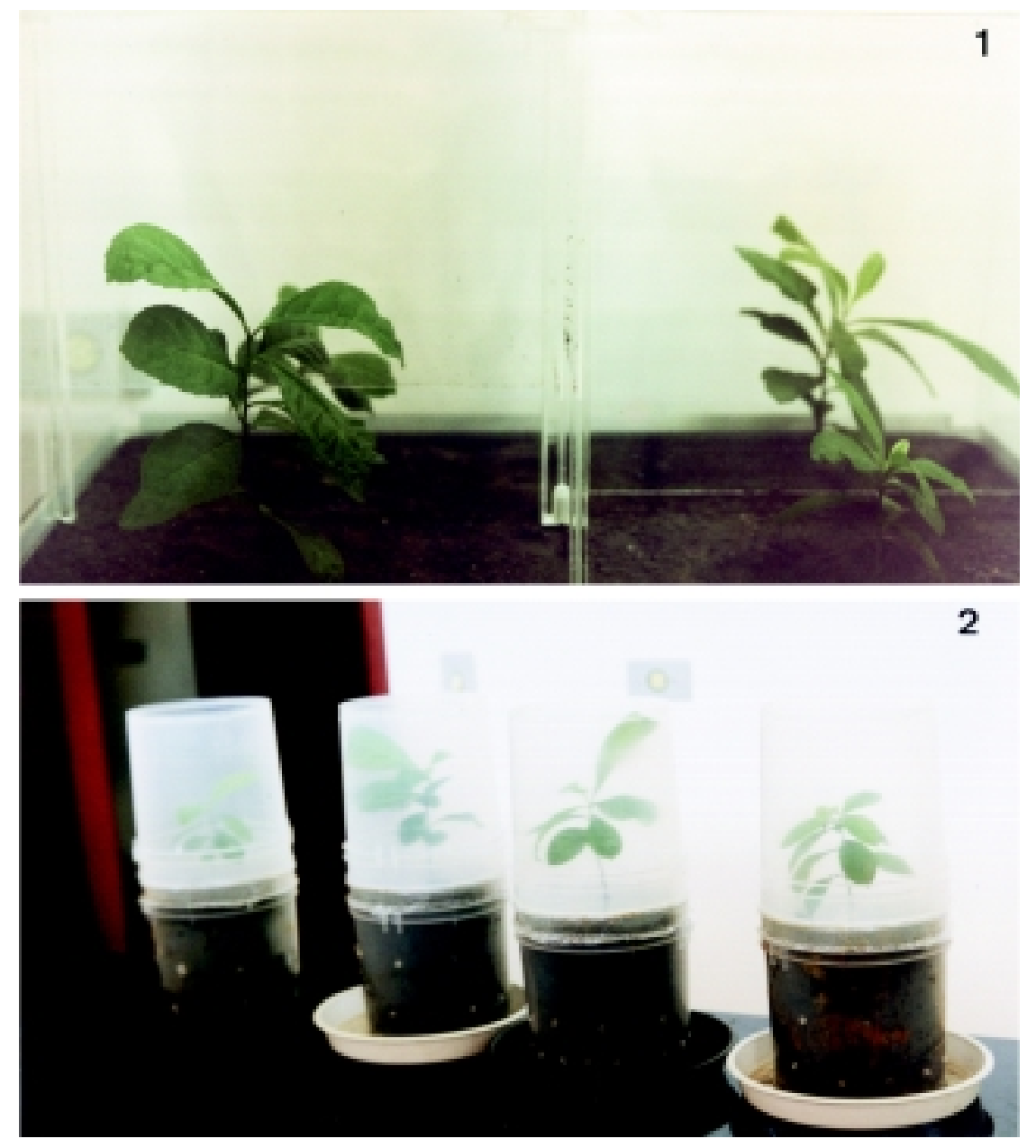

Figs 1-2. Gaiolas para criação de Gyropsilla spegazziniana. 1, gaiola de acrílico. 2, gaiolas plásticas. 

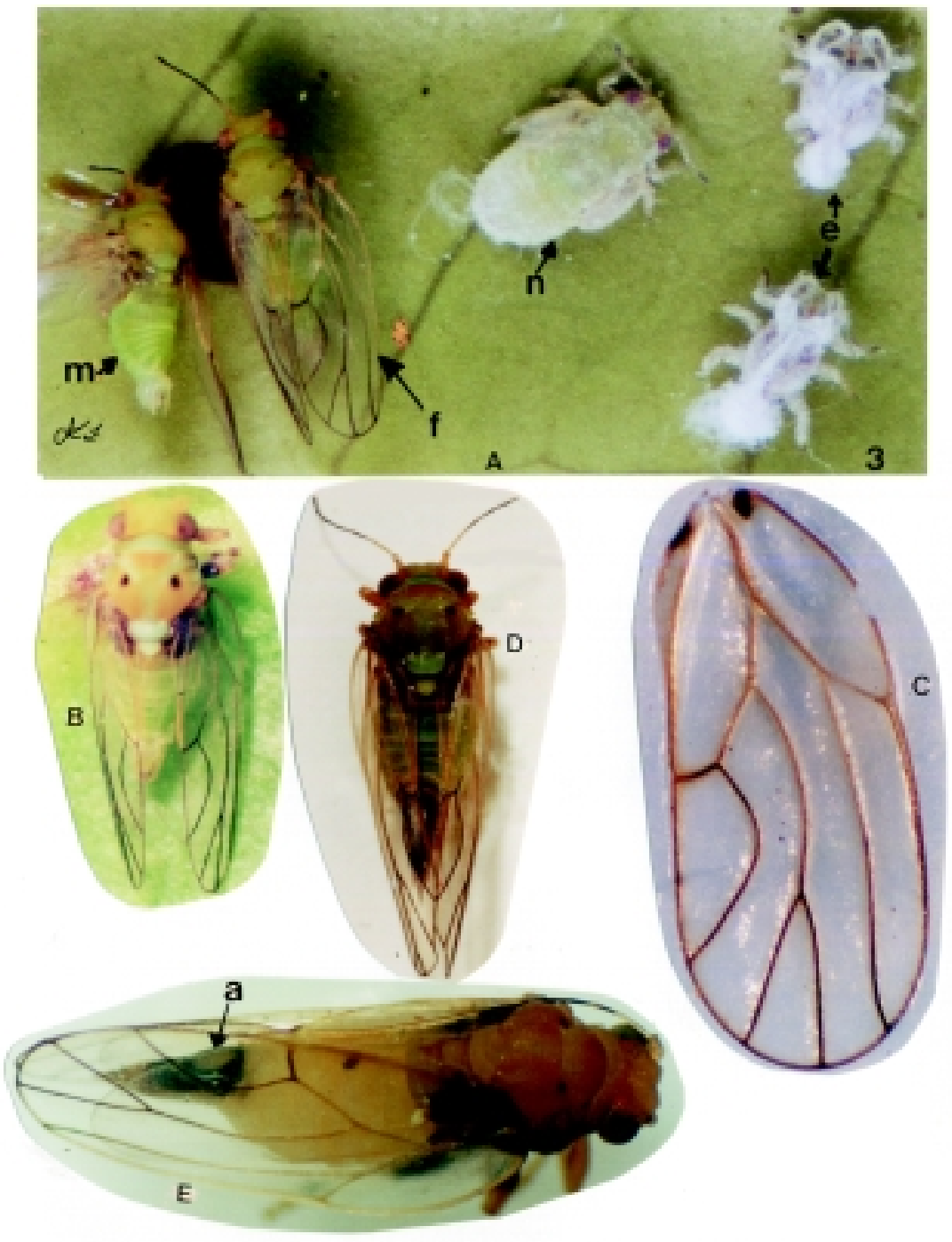

Fig. 3. Gyropsilla spegazziniana - A, adultos, ninfa de $5^{\circ}$ estádio e exúvias; B, macho. C, tégmina; D-E, fêmeas; a, abertura anal; e, exúvia; n, ninfa de $5^{\circ}$ estádio; $\mathrm{m}$, macho; f, fêmea. 

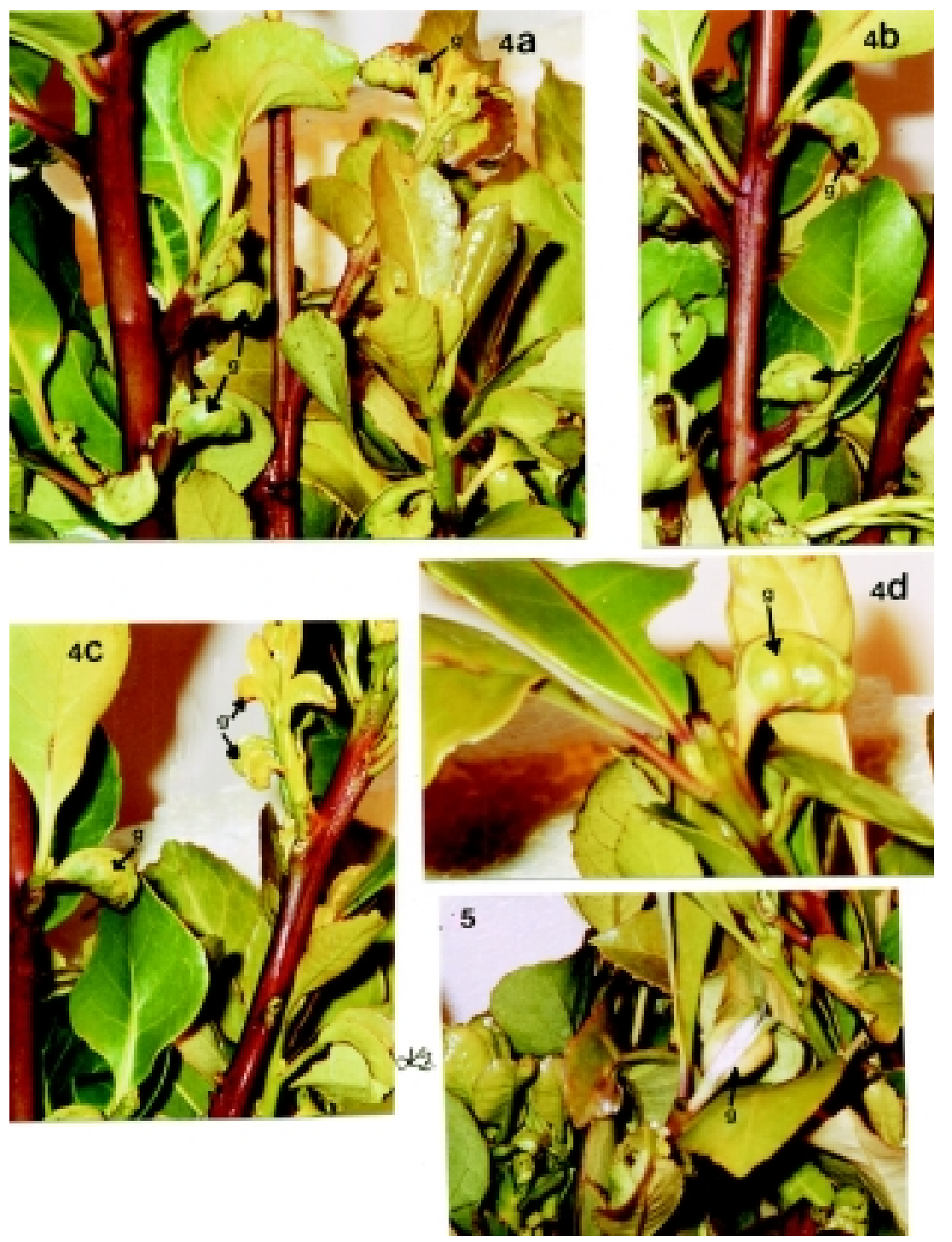

Figs 4-5. Galhas de Gyropsilla spegazziniana. 4 a-d, diversos estágios da galhas; 5, galha aberta; g, galha. 

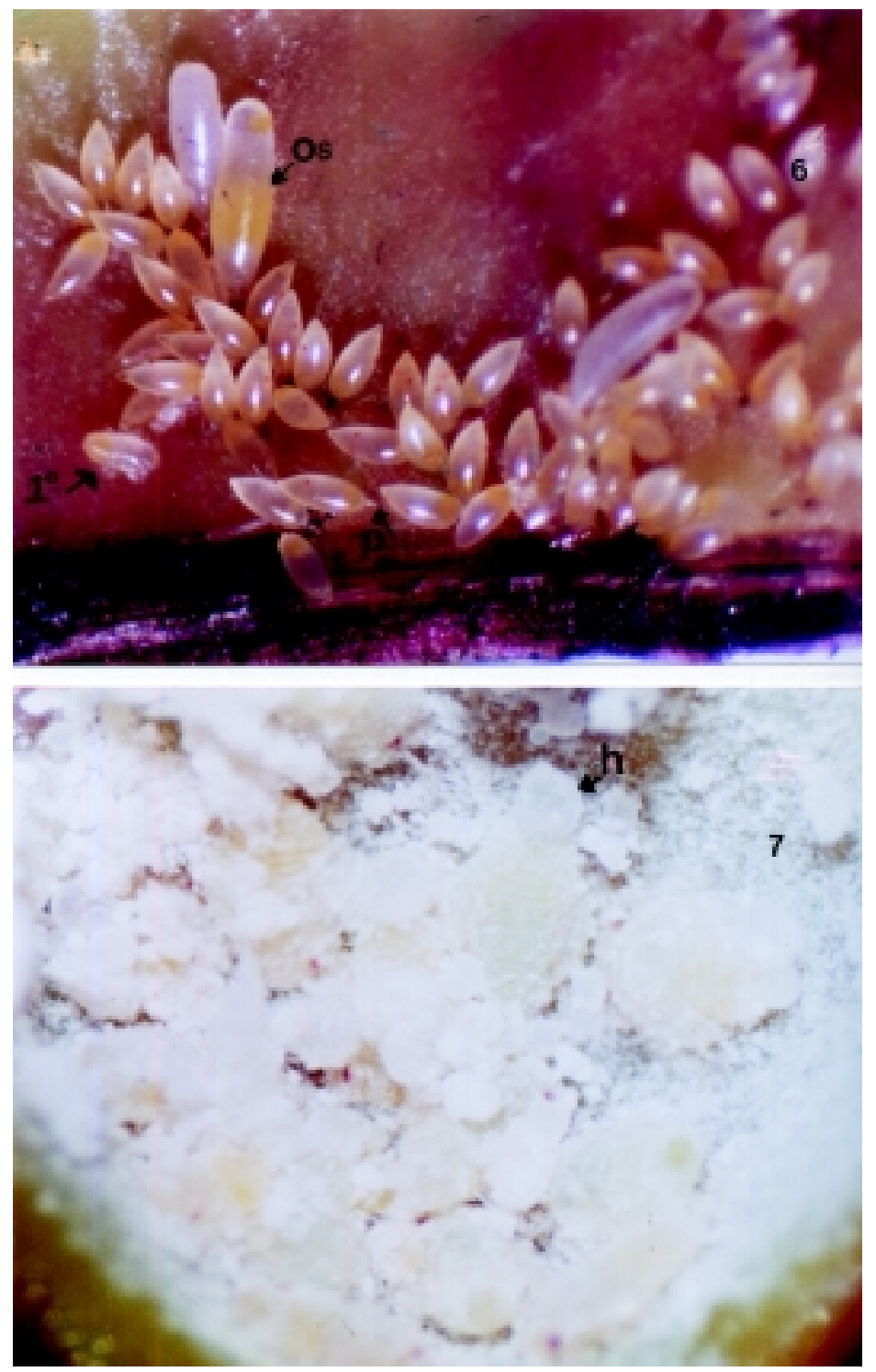

Figs 6 e 7. Gyropsilla spegazziniana -6 , ovos; 7, galha aberta com ninfas cobertas por substância pulvirolenta. Os, ovo de Sirphidae (Diptera); $1^{\circ}$, ninfa de $1^{\circ}$ estádio; P, pedúnculo; $\mathrm{h}$, gota de "honeydew". 


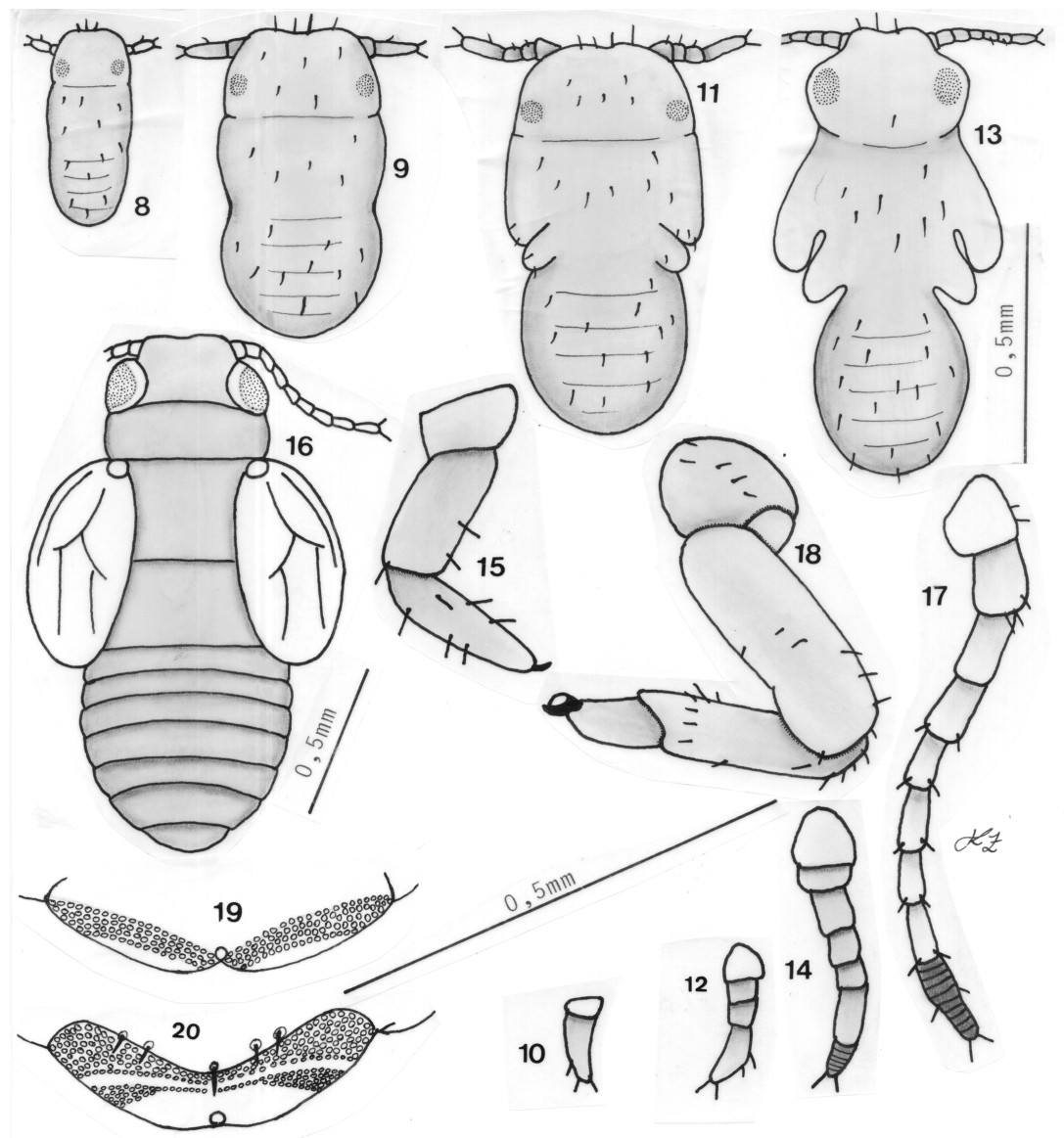

Figs 8 - 20. Gyropsilla spegazziniana. 8 , ninfa de $1^{\circ}$ estádio; 9 , ninfa de $2^{\circ}$ estádio; 10 , antena ( $2^{\circ}$ estádio); 11 , ninfa de $3^{\circ}$ estádio; 12 , antena ( $3^{\circ}$ estádio); 13 , ninfa de $4^{\circ}$ estádio; 14 , antena ( $4^{\circ}$ estádio); 15 , perna metatorácica ( $4^{\circ}$ estádio); 16. Ninfa de $5^{\circ}$ estádio; 17 . Antena $\left(5^{\circ}\right.$ estádio); 18 , perna metatorácica ( $5^{\circ}$ estádio); 19 , apice do abdômen (ventral) $\left(5^{\circ}\right.$ estádio) ; 20 , apice do abdômen (dorsal) ( $5^{\circ}$ estádio) 


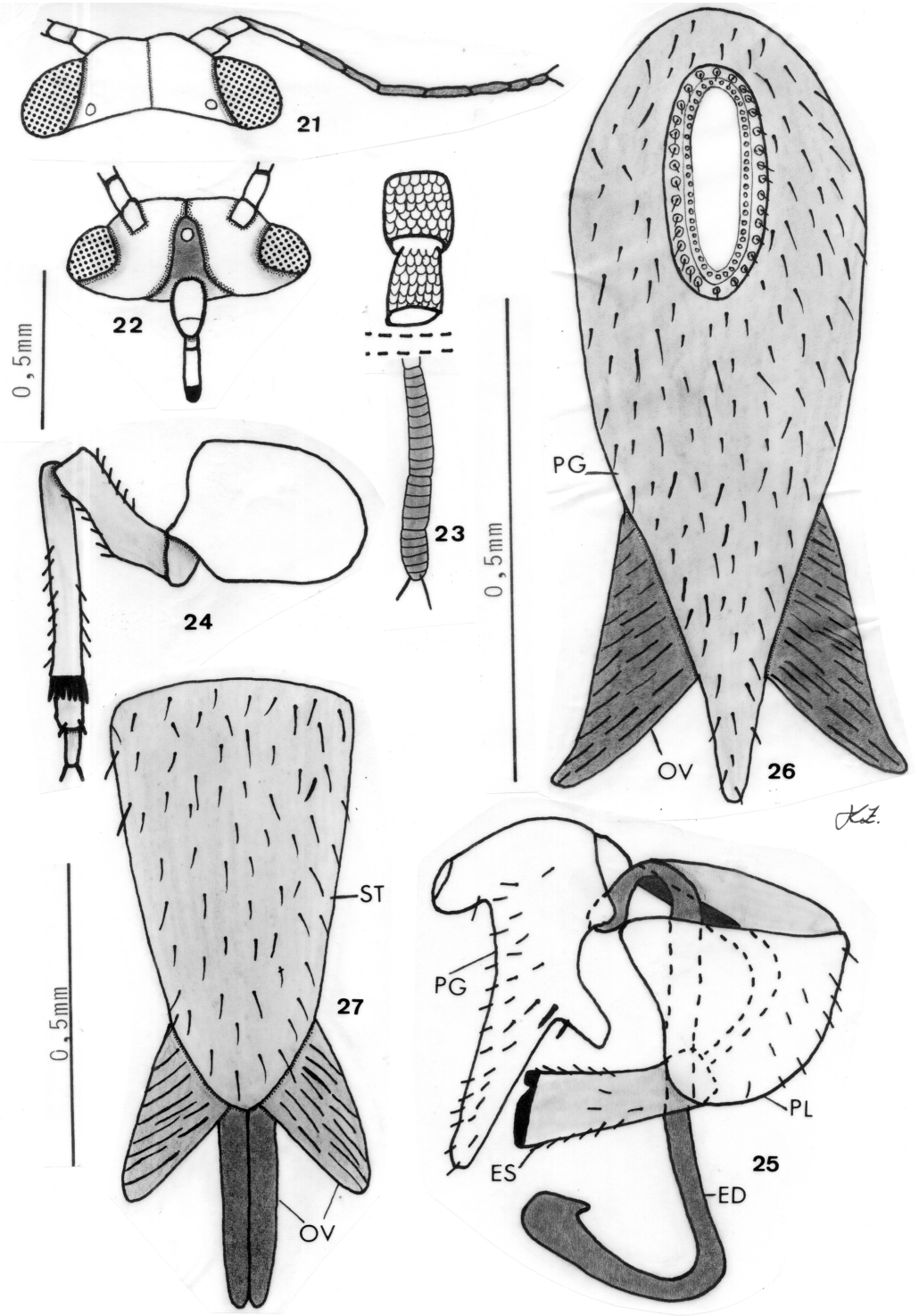

Figs 21-27. 21, cabeça (dorsal); 22, cabeça (ventral); 23, antena; 24, perna metatorácica; 25, terminália (macho); 26, pigóforo da fêmea (dorsal); 27, $7^{\circ}$ esterno e ovipositor. ED, edeago; ES, parâmero; OV, ovipositor; PG, pigóforo; PL, placa subgenital; ST, $7^{\circ}$ esterno. 